\title{
A Protective Canopy: Religious and Social Capital as Elements of a Theory of Religion and Health
}

\author{
Ephraim Shapiro ${ }^{1}[$
}

Accepted: 5 February 2021 / Published online: 1 March 2021

(c) The Author(s), under exclusive licence to Springer Science+Business Media, LLC part of Springer Nature 2021

\begin{abstract}
In order to help fill the gap in midrange theory for the religion-health connection, this paper reviews relevant literature on religious capital as well as social capital, a concept with which religious capital is sometimes incorrectly conflated. It identifies elements and mechanisms for each type of capital, including both quality and quantity, and describes evidence for their relationship with health. Expanding, unifying, and integrating these theoretical elements can help better understand the underlying mechanisms of the relationship between religion and health, with concomitant policy implications such as faith-based interventions as well as spur additional research on the topic.
\end{abstract}

Keywords Religion $\cdot$ Health $\cdot$ Theory $\cdot$ Religious capital $\cdot$ Social capital

\section{Introduction}

\section{Religion and Health}

There is a substantial and growing body of evidence that there is a connection between religion and health, one that is largely positive and beneficial although it can be negative as well (Ellison and Levin 1998; Levin 2001; Koenig et al. 2012; Idler 2014; Oman 2018). Numerous studies have found that religion can potentially affect mortality and morbidity through decreasing the incidence and severity of different types of illnesses, both physical and mental (Chatters 2000; Koenig et al. 2012; Pargament 2013; Oman 2018). Religion has also has been linked to improved health behaviors (Hill et al 2007; Krause et al. 2017; Shapiro 2018).

The connection between religion and health has multiple theoretical elements. A theoretical framework can play an important role in resolving disputes about the

Ephraim Shapiro

eas97@caa.columbia.edu

1 Department of Health Systems Management, Ariel University, 4 Kiryat Hamada, 40700 Ariel, Israel 
extent and nature of the relationship between religion and health; it can provide guidance as to which alternative interpretation of findings is the most logical (Hummer 2005). Further, it is not always clear in cross-sectional studies whether religion is influencing people's health or if people's health issues draw them to religion (Sloan 2006; Koenig, King, and Carson 2012; Hvidt et al. 2017). While not negating the importance of appropriate research methodology when studying religion and health (Rier et al. 2008; Koenig 2011), theory can be vital in helping to guide development of new measures, designing research, and interpreting complex results.

Even those who do think that religion can positively influence health point out that there is an inadequate understanding of the mechanisms by which religious involvement can impact health. In recent years, leading scholars in the field of religion and health research have stressed the lack of sufficient midrange theory in this area what Krause (2011) described as the need to make sense of a "disheveled literature". The literature about religion and health has grown substantially since then, yet the need for such theory still exists (Levin 2017).

In an effort to strengthen the theoretical foundations underlying the relationship between religion and health, this paper describes how not only the quantity and quality of social capital can influence health but also elements of religion itself such as rituals, knowledge and beliefs, or what some have called "religious capital". These constructs can potentially play an important role in explaining the relationship between religious involvement and health yet the theory needs to be fleshed out; the concept of religious capital in particular has rarely been used in the context of its relationship with health.

A better understanding of the social and religious reasons for this relationship can have important policy implications and present opportunities to reduce health inequalities. In order to help fill this gap and advance the midrange theory for the religion-health connection, this paper will review key literature on religious capital as well as of social capital, a concept with which religious capital is sometimes inappropriately conflated. The paper will identify elements and mechanisms for both types of capital, describe their relationship with each other and with health outcomes and summarize key supporting evidence.

\section{Social Capital, Religion and Health}

The importance of social resources was observed long ago. Durkheim ([1897] 1951) found that social groups, especially religious ones, can possess characteristics based on factors such as social integration and social cohesion which can affect healthrelated outcomes, most famously for suicide. Later sociologists showed that belonging to a community of people that share trust and support has multiple benefits, including improved health (Putnam 2000; Krause 2011). Religious involvement increases social network size and density and provides social support from people on whom one can count (Ellison and Sherkat 1995).

Building upon these ideas is the concept of social capital. Although there are a number of definitions of social capital, it typically involves accumulation of social resources that inhere in social relationships through being a part of a social network 
or other social structures (Bourdieu 1986; Coleman 1988; Portes 1998). For Putnam (2000), who has helped popularize the idea of social capital in recent years, it denotes features of social organization, such as trust, norms, and networks that can facilitate coordinated actions.

The most well established consequence of social capital seems to be in the area of health (Putnam 2000; Berkman et al. 2014; Idler 2014). Social capital is associated with a variety of health outcomes and in general there is a positive relationship (Ferlander 2007; Berkman et al. 2014). A growing number of studies provide both extensive theoretical background and evidentiary support for a generally positive relationship between social capital and health status, although more research is still needed (Szreter and Woolcock 2004; Gilbert et al. 2013; Folland and Rocco 2014).

Social capital is a prominent feature of religious involvement in particular (Smidt 2003; Idler 2014). Religious communities are thought to be important sources of social capital, perhaps even the largest source of social capital in the U.S. (Putnam 2000; Putnam and Campbell 2010). There is substantial evidence of a largely positive relationship between social capital and health among the religious involved; the relationship is a complex one, however, with variations by a number of dimensions (Yeary 2012; Plunkett 2016; Shapiro and Sharony 2018).

There are a number of hypothesized reasons for the relationship between social capital, religion, and health and social capital has been found to be a mediator for the relationship between religion and health (Yeary 2012). Social support of the religious institution and its members can also result in direct instrumental assistance to congregants (Levin 1996; Chatters 2000). Religious institutions and leaders can also serve as facilitators and gatekeepers for health-seeking behaviors (Garcia et al. 2013), especially for poor and vulnerable populations (Chatters 2000; Trinitapoli et al. 2009). Community health workers in religious institutions partnering with the health care system can provide direct care or help enable medical visits (Islam et al. 2013; Galiatsatos et al. 2016). Social capital can also enable groups to affect health outcomes through influencing political processes by joining forces with others (Szreter and Woolcock 2004; Foley and Hoge 2007).

It is important to note that the impact of social capital can be negative as well (Portes 1998). Whereas social networks normally have positive effects, they can also be destructive. When group beliefs discourage healthful behaviors or encourage deleterious behaviors, they can have a negative impact as the social resources can be harmful. For example, stigma related to mental health disease in the most traditional parts of the Jewish community may depress appropriate utilization of behavioral health services (Greenberg and Witzum 2013).

\section{Social Capital Magnified, Religion, and Health}

Not only the quantity but the quality of social capital may be greater among religious communities. The mechanisms by which social capital can have an impact in general and for health in particular, function especially well in the context of a religious community, as described below. I use the term "social capital magnified" to 
refer to this intensified overall effect of social capital that can potentially accompany religious involvement, such as church-going.

Religious communities and institutionalized religion in general can magnify the impact of social capital through normative socialization and social control. Religion's moral authority can regulate individuals' behaviors. Beliefs and practices can unite adherents into a single moral community such as a church, mosque, or synagogue. The power and significance of believing in the same god(s) and in a shared set of religious values also helps unify members into a strongly cohesive group; many denominations have a level of authority not found in secular organizations, thus magnifying their impact.

The environment for religious involvement typically involves rules and norms governing activities in that community. These norms may help to form especially strong bonds among congregants through strengthening group coherence and relationships, and through the actual content of the norms, such as a sense of responsibility toward others. Constructs such as social networks, cohesion, and support seem to play an especially large role in religious communities (Chatters 2000; Smidt 2003; Foley and Hoge 2007; Putnam and Campbell 2010).

Religious communities and institutions are concerned with ensuring that people have shared expectations and that they abide by norms and keep obligations. They promote and share values, traditions, and texts. Religion can influence people's health through mediating religious individuals' lifestyle based on these shared norms and obligations. Religions describe rewards for adherence to prescribed behaviors as well as sanctions against individual disregard of them. For example, the disproportionate influence of others in a religious community may increase adherence to communal teachings and laws, such as avoiding harmful activities, which can potentially affect health (Idler 2014; Krause et al 2017).

Religious communities can foster an especially high level among their members of trust, a very important element of social capital. Religious participants feel more confident that others in the group can be counted on and that credits accrued through their actions will be reciprocated in future. Whereas studies document the benefits of having friends in general (Berkman et al. 2014), the network of friends from church seem to be especially helpful and their impact magnified; a friendship network of the religiously involved, such as churchgoers, can have a more powerful impact; as a result, friends in a religious community have been labeled "supercharged" friends (Putnam and Campbell 2010).

In ways that often differ from leaders of secular organizations, religious leaders can also have increased influence over the behaviors of congregants in ways related to social capital. Research has found that religious leaders serve as especially effective role models (Levin 1996), and their congregations can constitute a reference group for proper behavioral norms (Ellison and Sherkat 1995; Chatters 2000). Health initiatives can leverage the influence of religious leaders to successfully change the behavior of their congregants through interventions (Padela et al. 2011). Leaders can play critical roles in building community and meeting the needs of church goers (Foley and Hoge 2007).

There can also be a negative health impact of social capital in religious communities as conflicts with group norms become intensified. For example, religious 
struggles can be harmful to health if someone feels abandoned by his or her religion, leading to negative coping with illness (Ellison and Lee 2010; Pargament 2013). Intensity of commitment to a religious community may also have negative implications when organizational conflicts lead to disputes between members and interpersonal struggles can be more stressful in a religious context and harm well-being (Krause 2005; Ellison and Lee 2010).

\section{Religious Capital and Health}

While social capital is an important determinant of health, it is critical to go beyond merely looking at the role of religion in a social context and to examine how the specific content of religion itself can potentially influence health. There are distinctive aspects of religion such as beliefs, behaviors, rituals, and perspectives that can serve as a resource (Iannacone 1990, 1994; Stark and Finke 2000; Finke and Daugherty 2002). The term "religious capital" can be used to denote these aspects of religion.

Religious capital involves the degree of mastery of a religious culture (Stark and Finke 2000). It includes learning the teachings, skills, and rituals of a specific religion such as stories from sacred literature, specific rituals, and liturgies (lannaccone 1990; Finke and Daugherty 2002). In addition to a learned mastery of a religion, however; religious capital also includes an attachment to a particular religious culture, based on emotion as well as intellect. Religious activities such as prayer, rituals, and mystical experiences build up over a lifetime, not only increasing knowledge, but strengthening emotional ties to a religion (Stark and Finke 2000, Finke and Daugherty 2002).

The term "Religious Capital" was developed by an economist, and it has most often been used mainly in economic contexts ((Iannacone 1990; Barker 2008). However, this role of religion in our lives can affect attitudes and behaviors which can impact health, potentially in a positive way. Whereas Marx ([1843] 1978) famously disparaged religion as an "opium of the people", Stark and Finke (2000) wrote that religion is the "amphetamine of the people", providing drive to their behavior and motivating social change; they thought that religion is not just a set of social activities but is based on critical underlying ideas from oral and written traditions that affects attitudes and influence behaviors.

Religious capital can be expected to be associated with health. Factors related to the nature of religion, such as theology, play an important if often neglected role in studies of the impact of religious involvement on health (Levin 1996, 2009; Krause et al. 2017). Not just the social context but the specific content of a religion's beliefs matters. Religious doctrines can lead to a perspective on human nature and society that leads to attitudes associated with better physical and mental health outcomes (Chatters 2000; Levin 2001; Krause et al. 2017).

An important aspect of religious participation is that it is not merely a discrete activity like bowling or volunteering but part of a distinct perspective and worldview that often permeates thoughts and behaviors even when not performing religious acts, thus reinforcing their impact. The idea of the sacred and of transcendence, parts of the basic definition of religion, underlies the wider perspective that 
religion provides (Durkheim [1912] 1965); Berger 1967; Stark and Finke 2000; Hill and Pargament 2003. A belief in transcendental rewards and punishment is likely to increase adherence to religious doctrines which could affect health for very different reasons than social capital and influences of other social factors which are not considered obligatory or connected to the transcendental. For example, belief in the New Testament idea that "my body is a temple" can have a positive impact on health (Krause et al. 2017).

As a result, health interventions such as improved health behaviors may be more effective when placed in the context of elements of a religion such as its values (Berkman et al. 2014; Idler 2014). Specific religious doctrines and beliefs can also have generally protective benefits which can serve as part of religion's protective role. Religious proscriptions and prescriptions can affect behaviors associated with health status such as smoking, substance abuse, risky sex, nutrition, and exercise (Ellison 1995; Levin 1996; Levin 2001; Hill et al 2007; Idler 2014;).

Prosocial behaviors can also be related to religious beliefs and at the same time can also affect health. For example, volunteering can increase religious capital (Park and Smith 2000) and also improve the health of the volunteers themselves as well as those for whom services are being performed (Kim and Konrath 2016).

It is important to stress that, as with social capital, religious capital does not always have a positive impact on health. Some theological beliefs can harm health. For example, adherence to religious explanations for illness, such as sin, and reliance on divine intervention for a cure may interfere with medically appropriate care seeking and affect mortality as well as disease. A perception of sacred loss normally has a negative effect on health, although a stronger sense of meaning in life can mitigate the negative effect (Krause et al 2018). Further, resistance to vaccination among religious communities continues to be a contentious and complex issue (Bock 2020), although it is possible that could change after the coronavirus pandemic.

\section{Case Studies}

Although elements of religious capital can potentially impact health, they have been given less attention than social capital or the impact of religion on health outcomes has been inappropriately attributed to social capital. To the extent that the elements of religious capital have previously been used in research, there is at least some support for the theoretical constructs presented above, even if earlier studies do not fully operationalize the concept and/or do not always test them directly. Two case studies are presented below to illustrate how the idea that religious capital, as distinct from social capital, can potentially be an important theoretical concept yet there is a need to operationalize the theory.

Abraido-Lanza et al. (2004) attempted to better understand the mechanisms that mediate the relationship between coping and health. In order to do so, they tested a theoretical model concerning religion, coping; pain and psychological adjustment by surveying a sample of 200 Latinos in New York City with arthritis using path analysis methodology. The items used in the study involved specific forms of religious coping (such as the use of prayer; the request for help from God; and religious 
faith, trust, and comfort) derived from previously validated scales among people with arthritis.

The authors found that religious coping was associated with greater mental wellbeing, and found high levels of religious coping in the sample, which was associated with active, action-oriented responses to pain. Participants described how their faith in God helped them overcome severe pain and take command of their disease.

The authors concluded that religion is an important form of coping for Latinos with arthritis and that researchers studying coping and psychosocial processes among Latino populations should use scales measuring religious coping. The study points to the importance of including an adequate number of religious items in studies which may be potential elements of religious capital, when assessing coping with illness in addition to social and psychological factors. The study's findings also suggest the intertwining of religious capital with other identities such as ethnicity in potentially impacting health.

More recently, Holt et al (2012) examined determinants of health among AfricanAmerican communities. The authors made a pioneering effort to try to distinguish between social capital and religious capital and to operationalize the latter concept to at least a limited extent. They surveyed 803 African-Americans, developing separate measures for social capital and religious capital as well as measuring spiritual capital and religiosity.

The social capital instrument used to develop capital instruments was a nine-item measure comprised of three factors: social support, interconnectedness, and community participation. The religious capital scale was a nine-item scale based on the social capital instrument. For example, the instrument included questions such as: "If a medical emergency arose in my home, I would be likely to call on someone in my religious/spiritual community for help" and "Most people in my religious/spiritual community can be trusted."

The authors analyzed the associations between these scales and physical and mental health outcomes including self-rated health status and depressive symptoms. They found that the religious/ spiritual capital instruments appeared to have good initial reliability and validity, although were associated with only a few health outcomes. They concluded that the population of African-Americans sampled receives a substantial amount of capital from their faith-based community, especially from their relationship with a higher power (eg. God), supporting the importance of attempting to better understand and measure elements of religious capital.

\section{Discussion}

Religion can affect many aspects of a person's life, including health-related ones. To adapt Berger's (1967) phrase, there is abundant research that religion is not only a "sacred canopy" but can serve as a "protective canopy" in terms of health (Koenig et al. 2012; Idler 2014; Oman 2018). A theoretical framework for a connection between religious capital and health above and beyond social capital can help fill some of the gap in midrange theory about religion and health. This paper aimed to advance the theoretical framework for the relationship between religion 
and health through elaboration of a theory of religion and health and a review of key relevant literature. It described how the concept of "social capital" is critical in understanding this relationship, an observation found elsewhere (Smidt 2003; Idler 2014; Shapiro and Sharony 2018). Evidence was presented that not only the quantity but also the quality of social capital, or what may be termed "social capital magnified" is an important mechanism by which religion can influence health through intensified impact of social capital, something that has less commonly been noted.

Above and beyond social factors, there are elements of religion itself such as rituals, knowledge and beliefs, prescriptions and proscriptions, and the emotional connection to them or what may be called "religious capital." This is a concept has been used in the literature before but relatively infrequently, and rarely in the context of religion and health. This form of capital can play an important role in explaining the relationship between religious involvement and health.

Religion is an important part of the causal pathway in which other factors work to affect health (Levin 1996, 2009; Chatters 2000; Ellison and Hummer 2010; Krause 2011; Krause et al. 2017; Oman 2018). While some of the distinctive elements of religious capital and their relationship to forms of social capital have been noted before, (Shapiro 2011; Koenig et al. 2012; Oman 2018), unifying and integrating them in a coherent manner that can make them more useful in understanding the reasons for the relationship between religion and health. A better theoretical understanding of the religion-health connection can deepen and improve analyses of what affects health, with resultant implications. This paper could potentially make an important contribution to midrange theory and its development. To our knowledge, there is no literature describing a detailed theory of religious capital and health as this paper attempts to do.

This paper argues that there is a need to focus on the quality of social capital not only the quantity of it, especially in a religious context, and there is indeed a large and growing body of literature about the connection of social capital, religion, and health. Despite the potential importance of religion to health in addition to social factors, however, there has been surprisingly little attention paid to the idea of religious capital, especially in comparison to social factors such as social capital. Too often religious capital has been considered an aspect of social capital.

It appears that in contrast to social capital there is very little literature about religious capital which can also potentially play an important role in understanding the relationship between religion and health as described in this paper. For example, a search of the Pubmed database using the key words "social capital" and "health" found well over 3000 results. However, a search for "religious capital" and "health" found virtually no articles.

It should be noted, that while there is a paucity of literature about religious capital and health, theories are not created out of whole cloth, and this paper builds upon the work of earlier authors including the case studies mentioned earlier (AbraidoLanza et al. 2004; Holt et al. 2012). The earlier research suggests pathways by which the concept can be used. Both earlier studies present important if limited elements of religious capital, with one article focusing on coping and one on some communal aspects of religion. 
However, in the Abraido-Lanza paper, religion is treated a form of psychosocial resource, not put in a separate theoretical framework related to religion. The Holt paper does mention religious capital but presents it as a limited model using a tool based on one developed for social capital. Like social capital which built upon earlier elements such as social cohesion and trust, some elements of religious capital such as coping or beliefs certainly existed before. However, as with social capital, building upon and unifying earlier elements unto one theory is pivotal in making the concept useful for future health-related research. It is hoped that the current paper will encourage such research by unifying the elements and facilitating better operationalizing the concept. While it may be overly ambitious for religious capital to play as important a role in understanding determinants of health as social capital currently does, there is at least potential for it to make an important contribution in health-related research.

For example, recent studies used church attendance as a proxy for religious capital among minorities in the United States (Shapiro 2018; Scott et al. 2018). They found that greater church attendance was generally associated with some but not all health behaviors and hypothesized that religious capital played a role in the results. However, the studies were not able to measure religious capital directly. Operationalization of religious capital would have been useful in such research. Further, the study by Holt et al. (2012) suggested that religious capital is not associated with all health outcome and/or all populations. More research in this area is needed.

There is also potential for expansion and sharpening of the model presented by others. There may be different types of religious capital just as there are different types of social capital. For example, there may be one type for knowledge-based religious capital and one for emotions-based religious capital, two important aspects of religious capital described above.

It should be emphasized that the social and religious aspects of religion are not completely discrete factors and can be interrelated. Although a distinct mechanism, religious capital is theorized to work with social capital and other social resources to influence health as religious orientations and practices are reinforced and supported in a religious communal context (George et al. 2002). For example, increased social capital can lead to increased performance of religious activities and/or greater sharing of religious knowledge when one participates in a religious community. The relationship can work in the other direction as well. For example, increased religious capital can increase participation in religious services (Corcoran 2012), thereby increasing social capital through an expanded network (Putnam 2000).

However, one should be careful not to conflate social and religious capital too much because there are important differences. For example, whereas social capital typically involves expectations of reciprocity of rewards from other people, this is less so with religious capital which emphasizes altruism. For the religiously committed, the most valuable of all rewards is often otherworldly and can even include actions against one's self-interest. As a result, unlike conventional social capital, it is more likely that someone will provide resources to others in a religious context even in situations where reciprocity from other group members is not assured. Similarly, some have described religion as a "support convoy" because people expect help but 
know it may not be from the person they helped or may not even be from someone in their network (Kahn and Antonucci 1980).

There can also be interactions between demographic factors, religious capital, and social capital. The relationship between religious and social variables can be intertwined with several demographic factors. The potential impact of religion on health should not be examined in isolation from sociocultural environments, which can affect both the needs of different demographic groups and how they interact with the health care system (Stark and Finke 2000; Foley and Hoge 2007; Nicholson et al. 2009). The relationship of religion and health can vary across a number of dimensions such as gender, age, ethnicity, and migration status (Viladrich and Abraído-Lanza 2009; Nicholson et al. 2009; Koenig et al. 2012; Holt et al., 2012; Shapiro 2018). Values and cultural characteristics shared with other members of a congregation can facilitate social capital and sharing of support and resources, with positive effects on health. The extent to which a given religious community is composed of individuals from the same ethnicity or country could impact attitudes and behaviors that affect health directly or indirectly (Foley and Hoge 2007; Viladrich and Abraído-Lanza 2009).

Varying religious traditions also shape variations among denominations in ways that can affect their congregants' health through differing amounts and types of social and religious capital. For example, whereas some denominations focus on building close ties and fellowship, others focus more on building communities through activities and relation with external groups. The former tend to be conservative Protestant congregations whereas the latter tend to be Catholics (Foley and Hoge 2007). Churches with more prohibitions and penalties can exert more control over members in limiting harmful health behaviors (Iannacone 1994) and can possess more religious capital, with its attendant benefits. Certain Jewish religious streams may be especially cohesive and insular (Rier et al. 2008).

It should be noted that there also has been some research about the relationship of a seemingly related concept, spiritual capital, with health. There is evidence of a positive relationship between spiritual capital and health and well-being (Friedli 2001; Holt et al 2012; Park et al. 2020). However, in addition to a paucity of studies about spiritual capital and health, there has been a lack of agreement about how to define the concept of spiritual capital, as is the case with defining spirituality itself (Koenig 2011). Therefore, results of these studies should be interpreted with caution in understanding the relationship of religious capital and health but, although beyond the scope of this paper, the relationship between spiritual capital and health warrants a separate examination.

\section{Policy Implications}

The theoretical elements described above can help policymakers, researchers, and others to better understand the underpinnings of the important role that faith communities can play in people's lives, especially those of vulnerable populations. Although some speak of individual responsibility needed to live a healthy lifestyle, the context in which people live can make choosing healthy behaviors much 
easier. Social and religious capital can be leveraged to provide such a helpful context. Policies and programs can be developed and implemented to take advantage of these opportunities in potentially addressing improving population health and reducing health inequalities (Campbell et al. 2007; Idler 2014; Oman 2018).

Some would claim that any relationships between religious involvement and health are spurious or merely because of social resources rather than any distinctive elements (Sloan 2006); yet others could argue that there is little need to target the religiously involved in health promotion initiatives because they already are in better health. However, not all who attend services are in very good health and while some congregations sponsor health-related programs, many do not. There is a potential opportunity to promote the health of those who are religious by taking advantage of religious as well as social capital, especially for vulnerable populations.

A focus on religious traditions has the potential to improve prevention, not just care (Idler 2014; Rozier 2017; Oman 2018). Congregations and their leaders can undertake a variety of initiatives to promote health (Campbell et al. 2007; Padela 2011; Galiatsatos et al. 2016). For example, lay health ministries, faith-based community health workers, and healthy cooking classes adhering to the dietary restrictions are all examples of faith-based interventions that have a religious component, not merely a social one with potential positive impacts on health.

Although religious and social capital are concepts distinct from financial capital, they may also have implications for costs. Religion is associated with generally improved health and can serve as a cost-effective way to improve health, thus reduce health care spending. For example, volunteering is more prevalent among those who are religious and who may have differing motivations than those in the general population (Putnam and Campbell 2010).

\section{Additional Research}

The mechanisms by which religious capital and, to a lesser extent, social capital function are not fully understood. Additional research is needed to better understand the mechanisms by which religious capital and social capital, often magnified in a religious context, can affect health. Fleshing out the theories based on the literature cited in this paper and connecting them more explicitly can enable better operationalization and testing of the theories, especially in relation to the understanding the underlying mechanisms of the relationship between religion and health. In particular, understanding the independent and joint contributions of social capital and religious capital could have implications as to optimal design of interventions to improve the health of the religiously involved among vulnerable populations. It would be useful to better understand both the negative as well as positive aspects of the relationship between religion and health. In addition, religious and social capital can potentially affect even those who participate within a faith community but are not religious themselves, although the extent to which they apply for these people is unclear. It would therefore be helpful to perform additional research as to how 
the motivation for and content of religious service attendance affect associations between religious capital, social capital, and health.

\section{Conclusions}

In an effort to strengthen the understanding of the relationship between religious involvement and health, this article presents literature to support a theoretical framework that includes not just the quantity of social capital but the quality of it. It shines a light on the concept of religious capital, an important idea which has rarely been used in a public health context. The article presents evidence of a connection between religion and health that is consistent with this framework and that has potentially important public policy implications.

The theoretical elements described and evidence from the literature presented to support it can potentially spur additional research to better understand the nature of the religion-health connection and its underlying mechanisms; in particular, it would be helpful to develop quantifiable measures such as specific forms of religious knowledge, beliefs and faith-based bonds among people, that are connected to both religion and health. While much remains to be investigated, it is hoped that the theoretical framework presented can provide ideas and impetus toward achieving this goal.

Acknowledgements The author would like to acknowledge the assistance of the following during the course of the preparation of this paper: Ana Abraído-Lanza, Ph.D., Angela Aidala, Ph.D., Joyce MoonHoward, Dr. PH, Nancy Foner, Ph.D., Courtney Bender, Ph.D., Karolynn Siegel, Ph.D.

\section{Compliance with Ethical Standards}

Conflict of interest I have no relevant conflicts of interest.

Ethical Approval This paper was written in compliance with my institution's ethical standards and without a source of funding.

\section{References}

Abraído-Lanza, A. F., Vasquez, E., \& Echeverría, S. E. (2004). En las manos de Dios [in God's hands]: Religious and other forms of coping among Latinos with arthritis. Journal of consulting and clinical psychology, 72(1), 91-102.

Barker, M. (2008). The role of religious capital in relating religion and economic development. Third Sector Review, 14(1), 23-34.

Berger, P. (1967). The sacred canopy: Elements of a sociological theory of religion. Garden City, N.Y: Doubleday.

Berkman, L. F., Kawachi, I., \& Glymour, M. (Eds.). (2014). Social epidemiology. New York, NY: Oxford University Press.

Bock, G. L. (2020). The end of religious exemptions from immunisation requirements? Journal of Medical Ethics, 46(2), 114. 
Bourdieu, P. (1986). The forms of capital. In J. Richardson (Ed.), Handbook of theory and research for the sociology of education. Greenwood: New York, NY.

Campbell, M. K., Hudson, M. A., Resnicow, K., Blakeney, N., Paxton, A., \& Baskin, M. (2007). Church-based health promotion interventions: Evidence and lessons learned. Annual Review of Public Health, 28, 213-234.

Chatters, L. M. (2000). Religion and health: Public health research and practice. Annual Review of Public Health, 21, 335-367.

Coleman, J. S. (1988). Social capital in the creation of human capital. American Journal of Sociology, 94, S95-S120.

Corcoran, K. E. (2012). Religious human capital revisited: Testing the effect of religious human capital on religious participation. Rationality and Society, 24(3), 343.

Durkheim, E. (1951). Suicide. New York: The Free Press.

Durkheim, E. (1965). The elementary forms of the religious life. New York: The Free Press.

Ellison, C. G., \& Hummer, R. (2010). Religion, families, and health: Population-based research in the United States. New Brunswick, NJ: Rutgers University Press.

Ellison, C. G., \& Lee, J. (2010). Spiritual struggles and psychological distress: Is there a dark side of religion. Social Indicators Research, 98(3), 501-517.

Ellison, C. G., \& Levin, J. S. (1998). The religion-health connection: Evidence, theory, and future directions. Health Education and Behavior, 25(6), 700-720.

Ellison, C. G., \& Sherkat, D. E. (1995). Is sociology the core discipline for the scientific study of religion? Social Forces, 73(4), 1255.

Ferlander, S. (2007). The importance of different forms of social capital for health. Acta Sociologica, 50(2), 115-128.

Finke, R., \& Dougherty, K. D. (2002). The effects of professional training: The social and religious capital acquired in seminaries. Journal for the Scientific Study of Religion, 41(1), 103-120.

Foley, M. W., \& Hoge, D. (2007). Religion and the new immigrants: How faith communities form our newest citizens. New York: Oxford University Press.

Folland, S., \& Rocco, L. (2014). The Economics of social capital and health: A conceptual and empirical roadmap. New Jersey: World Scientific Publishing Company.

Friedli, L. (2001). Social and spiritual capital: Building emotional resilience in communities and individuals. Political Theology, 2(2), 55-64.

Galiatsatos, P., Sundar, S., Qureshi, A., Ooi, G., Teague, P., \& Daniel Hale, W. (2016). Health promotion in the community: Impact of faith-based lay health educators in urban neighborhoods. Journal of Religion and Health, 55(3), 1089-1096.

Garcia, G., Ellison, C. G., Sunil, T. S., \& Hill, T. D. (2013). Religion and selected health behaviors among latinos in texas. Journal of Religion and Health, 52(1), 18-31.

George, L., Ellison, G., \& Larson, D. B. (2002). Explaining the relationships between religious involvement and health. Psychological Inquiry., 13(3), 190-200.

Gilbert, K. L., Quinn, S. C., Goodman, R. M., Butler, J., \& Wallace, J. (2013). A meta-analysis of social capital and health: A case for needed research. Journal of Health Psychology, 18(11), 1385-1399.

Greenberg, D., \& Witztum, E. (2013). Challenges and conflicts in the delivery of mental health services to ultra-orthodox Jews. Asian Journal of Psychiatry, 6(1), 71-73.

Hill, P. C., \& Pargament, K. I. (2003). Advances in the conceptualization and measurement of religion and spirituality: Implications for physical and mental health research. The American Psychologist, 58(1), 64-74.

HillEllisonBurdetteMusick, T. D. C. G. A. M. M. A. (2007). Religious involvement and healthy lifestyles: Evidence from the survey of texas adults. Annals of Behavioral Medicine, 34(2), 217-222.

Holt, C. L., Schulz, E., Williams, B., Clark, E. M., Wang, M. Q., \& Southward, P. L. (2012). Assessment of religious and spiritual capital in African American communities. Journal of Religion and Health, 51(4), 1061-1074

Hummer, R. A. (2005). Commentary: Understanding religious involvement and mortality risk in the United States: Comment on Bagiella, Hong, and Sloan. International Journal of Epidemiology, 34(2), 452-453.

Hvidt, N. C., Hvidtjørn, D., Christensen, K., Nielsen, J. B., \& Søndergaard, J. (2017). Faith moves mountains-mountains move faith: Two opposite epidemiological forces in research on religion and health. Journal of Religion and Health, 56(1), 294-304.

Iannaccone, L. R. (1990). Religious practice: A human capital approach. Journal for the Scientific Study of Religion, 29(3), 297-314. 
Iannaccone, L. R. (1994). Why strict churches are strong. American Journal of Sociology, 99(5), 1180-1211.

Idler, E. L. (2014). Religion as a social determinant of public health. New York, NY: Oxford University Press.

IslamWyattPatelShapiroTandonMukherjiTannerReyTrinh-Shevrin, Nl. S. E. D. B. M. M. C. (2013). Evaluation of a community health worker pilot intervention to improve diabetes management in Bangladeshi immigrants with type 2 diabetes in New York City. The Diabetes Educator., 39(4), 478-493.

Kahn, R., \& Antonucci, T. (1980). Convoys over the life course: Attachments, roles and social support. In P. Baltes \& O. Brim (Eds.), Life span development and behavior. New York, NY: Academic Press.

Kim, E. S., \& Konrath, S. H. (2016). Volunteering is prospectively associated with health care use among older adults. Social Science \& Medicine, 149, 122.

Koenig, H. (2011). Spirituality and health research: Methods, measurements, statistics, and resources. West Conshohocken, PA: Templeton Press.

Koenig, H. G., King, D., \& Carson, V. (2012). Handbook of religion and health. New York, NY: Oxford University Press.

Krause, N. (2005). Negative interaction and heart disease in late life: Exploring variations by socioeconomic status. Journal of Aging and Health, 17(1), 28-55.

Krause, N. (2011). Religion and health: Making sense of a disheveled literature. Journal of Religion and Health, 50(1), 20-35.

Krause, N., Hill, P. C., Emmons, R., Pargament, K. I., \& Ironson, G. (2017). Assessing the relationship between religious involvement and health behaviors. Health Education \& Behavior: The Official Publication of the Society for Public Health Education, 44(2), 278-284.

Krause, N., Pargament, K. I., \& Ironson, G. (2018). Meaning in life moderates the relationship between sacred Loss/Desecration and health. Journal for the Scientific Study of Religion, 57(2), 365-376.

Levin, J. (1996). How religion influences morbidity and health: reflections on natural history, salutogenesis and host resistance. Social Science and Medicine, 43(5), 849-864.

Levin, J. S. (2001). God, faith and health: Exploring the spirituality-healing connection. New York, NY: Wiley.

Levin, J. (2009). And let us make us a name: Reflections on the future of the religion and health field. Journal of Religion and Health, 48(2), 125-145.

Levin, J. (2017). "For they knew not what it was": Rethinking the tacit narrative history of religion and health research. Journal of Religion and Health, 56(1), 28-46.

Marx, Kl. (1978). The Marx-Engels Reader. In: Tucker, Robert and McClellan, David, (ed.) New York, NY: WW Norton

Nicholson, A., Rose, R., \& Bobak, M. (2009). Association between attendance at religious services and self-reported health in 22 european countries. Social Science and Medicine, 69(4), 519-528.

Oman, D. (Ed.). (2018). Why religion and spirituality matter for public health: Evidence, implications, and resources. New York, NY: Springer.

Padela, A. I., Killawi, A., Heisler, M., Demonner, S., \& Fetters, M. D. (2011). The role of imams in american muslim health: Perspectives of Muslim community leaders in southeast Michigan. Journal of Religion and Health, 50(2), 359-373.

Pargament, K. (2013). APA handbook of psychology, religion, and spirituality. Washington, DC: American Psychological Association.

Park, J. J., Dizon Jude, P. M., \& Moya, M. (2020). Spiritual capital in communities of color: Religion and spirituality as sources of community cultural wealth. The Urban Review, 52(1), 127-150.

Park, J. Z., \& Smith, C. (2000). "To whom much has been given": Religious capital and community voluntarism among churchgoing protestants. Journal for the Scientific Study of Religion, 39(3), 272-28.

Plunkett, R., Leipert, B., \& Olson, J. (2016). Exploring the influence of social determinants, social capital, and health expertise on health and the rural church. Journal of Holistic Nursing : Official Journal of the American Holistic Nurses' Association, 34(3), 236-243.

Portes, A. (1998). Social capital: Its origins and applications in modern sociology. Annual Review of Sociology, 24(1), 1-24.

Putnam, R. (2000). Bowling alone. New York, NY: Simon and Schuster.

Putnam, R., \& Campbell, D. (2010). American grace: How religion divides and unites us. New York, NY: Simon \& Schuster. 
Rier, D. A., Schwartzbaum, A., \& Heller, C. (2008). Methodological issues in studying an insular, traditional population: A women's health survey among Israeli haredi (ultra-orthodox) Jews. Women \& Health, 48(4), 363-381.

Rozier, M. (2017). Religion and public health: Moral tradition as both problem and solution. Journal of religion and health., 56(3), 1052-1063.

Scott, Lionel D., Jr., Hodge, D. R., White, T., \& Munson, M. R. (2018). Substance use among older youth transitioning from foster care: Examining the protective effects of religious and spiritual capital. Child \& Family Social Work. https://doi.org/10.1111/cfs.12429.

Shapiro, E. (2011). Religious Involvement and Latino Immigrant Health in Blasi, Anthony, (ed.), Toward a sociological theory of religion and health. pp.175-206. Leiden: Brill Publishers.

Shapiro, E. (2018). Places of habits and hearts: Church attendance and Latino immigrant health behaviors in The United States. Journal of Racial and Ethnic Health Disparities, 5(6), 1328-1336.

Shapiro, E., \& Sharony, C. (2018). Religious and social capital and health. In S. Folland \& E. Nauenberg (Eds.), The Elgar companion to social capital and health. Northampton, MA: Edward Elgar Academic Publishers.

Sloan, R. (2006). Blind Faith. New York, NY: St. Martin's Press.

Smidt, C. (2003). Religion as social capital: Producing the common good. Waco, TX: Baylor University Press.

Stark, R., \& Finke, R. (2000). Acts of Faith: Explaining the human side of religion. Berkeley, CA: University of California Press.

Szreter, S., \& Woolcock, M. (2004). Health by association? social capital, social theory, and the political economy of public health. International Journal of Epidemiology, 33(4), 650-667.

Trinitapoli, J., Ellison, C. G., \& Boardman, J. D. (2009). US religious congregations and the sponsorship of health-related programs. Social Science \& Medicine, 68(12), 2231-2239.

Viladrich, A., \& Abraído-Lanza, A. (2009). Religion and mental health among minorities and immigrants. In S. Loue \& M. Sajatovic (Eds.), Determinants of minority mental health and wellness. New York, NY: Springer.

Yeary, K., Ounpraseuth, S., Moore, P., Bursac, Z., \& Greene, P. (2012). Religion, social capital, and health. Review of Religious Research, 54(3), 331-347.

Publisher's Note Springer Nature remains neutral with regard to jurisdictional claims in published maps and institutional affiliations. 